\title{
TESTING EFFICACY OF BIRD DETERRENTS AT WIND TURBINE FACILITIES: A PILOT STUDY IN NOVA SCOTIA, CANADA
}

\author{
KATHERINE DOREY ${ }^{\text {a*; }}$ SCOTT DICKEY ${ }^{\text {b, }}$ \\ TONY R. WALKER ${ }^{\text {a }}$ \\ ${ }^{a}$ School for Resource and Environmental Studies, Dalhousie University, \\ Halifax, NS, B3H 4R2, Canada \\ ${ }^{b}$ Strum Consulting, Bedford, NS, B4A 1C5, Canada
}

\begin{abstract}
Wind energy has become one of the fastest-growing renewable electricity sources globally, and this trend is expected to continue. However, wind turbines cause avian mortality when birds collide with these structures. Although regulatory agencies in many jurisdictions require post-construction bird mortality monitoring at turbine sites, resulting mortality estimates are often imprecise and under-reported. This uncertainty is often attributed to searcher inefficiencies or scavenger losses. Furthermore, data regarding the effectiveness of active bird mortality mitigation at these facilities are also lacking. This pilot study assessed mitigation effectiveness of visual and audio deterrents, using predator owl deterrent models and bioacoustic alarm and predator calls deployed at a wind turbine facility in Nova Scotia, Canada. These deterrents did not deter birds from wind turbines in statistically significant ways, in comparison to control sites. Whilst results were inconclusive, it would be prudent to continue assessing mitigative options to minimize impacts on birds, considering the expected growth of the wind energy sector in Canada.
\end{abstract}

Keywords: Wind energy development; Wind turbines; Bird mortality monitoring; Bird deterrents; Bird mortality mitigation.

\section{INTRODUCTION}

Wind energy has become one of the fastest-growing renewable electricity sources in over 90 countries (Marques et al. 2014; CanWEA 2016), because it is a reliable, affordable, and relatively safe alternative to carbon-based energy sources. Wind energy in Canada continues to grow by $18 \%$ annually on average, with an installed capacity of 11,989 MW in 2016 (CanWEA 2016). With annual electricity consumption of 16 megawatt hours (MWh) per capita,

* Author to whom correspondence should be addressed: katherinedorey@hotmail.com 
Canada ranks fourth highest globally, reflecting an important need for energy efficiency, conservation, and renewable energy development (The World Bank Group 2016). Wind energy growth is also continuing in Nova Scotia, which has doubled its wind energy production from 2012 - 2016. As of December 2017, the province was producing $610 \mathrm{MW}$ of wind electricity, meeting 14\% of provincial energy needs (CanWEA 2017; Nova Scotia Power 2017). Nova Scotia ranks fourth in total installed capacity in Canada and is on track to meet $40 \%$ of its energy needs through renewable sources by 2020 (EGSPA 2007).

Although wind energy continues to provide a clean, reliable source of electricity, it is not without direct and indirect impacts. Wind turbines have significantly lower impacts on birds than traditional energy sources and other man-made structures (e.g., power lines and buildings) (Saidur et al. 2011; Calvert et al. 2013), but are still responsible for an estimated 0-40 bird mortalities/turbine/year (Sovacool 2013; Zimmerling et al. 2013).

However, many proponents are now employing mitigation techniques, and using an understanding of how passerine birds (the most impacted species guild from wind turbines in Atlantic Canada) use different habitats to strategically site turbines away from sensitive areas (Baisner et al.2010). This has led to reductions in avian mortality rates to as low as 0.02-7.36 birds/turbine/year (Wang et al. 2015).

In Canada, the Wind Energy Bird and Bat Monitoring Database (WEBBMD) is a joint initiative among Bird Studies Canada, Canadian Wind Energy Association (CanWEA), Environment and Climate Change Canada, and Ontario Ministry of Natural Resources (Bird Studies Canada, 2018). The database is used to understand characteristics of bird and bat mortality at wind farms across Canada. It currently relies heavily on data from Alberta and Ontario, the provinces from which most wind turbine monitoring results are submitted (WEBBMD 2016). Data from Atlantic Canada come from only 2 sites from New Brunswick, 3 in Prince Edward Island, 2 in Newfoundland and Labrador and 1 in Nova Scotia. Consequently, with the current data, researchers are unable to accurately assess mortality rates for Atlantic Canada, particularly Nova Scotia (WEBBMD 2016; Parisé and Walker 2017). In Atlantic Canada, the estimated average mortality rate is 1.17 birds/turbine/year, markedly lower than for Ontario (6.14) and Alberta (2.65) (WEBBMD 2016). Passerines represented the majority of bird mortalities recorded in Atlantic Canada (76.9\%), followed by 
gull mortalities (11.5\%). which likely reflects the coastal locations of wind farms for which data were submitted (WEBBMD 2016).

Many mitigation measures have been proposed and tested, ranging from sensory deterrents to turbine modifications. Beston et al. (2015) evaluated outcomes of various studies and found that many of these measures had inconclusive results. This is likely due to differences in geography and avian species present at each wind-energy site, highlighting the need for site-specific mitigation measures (Hull et al. 2013). It is often difficult to accurately quantify numbers of mortalities from wind turbines, due to error caused by searcher inefficiency, removal of carcasses by scavengers, and inconsistencies in data collection techniques (Smallwood et al. 2010; Zimmerling et al. 2013; Beston et al. 2015; Stenglein et al. 2015; Reyes et al. 2016). New studies have called for standardized post-construction monitoring techniques to address this (Parisé and Walker, 2017), and Zimerling et al. (2013) provide statistical correction factors to reduce error.

Although wind turbines present a lesser threat to birds than do other man-made structures (Calvert et al. 2013), the cumulative impacts of human-made structures are largely unknown, and assessing possible impacts to birds requires more research (Schuster et al. 2015). In Canada, all bird species are protected under the Migratory Birds Convention Act (MBCA 1994), and those at risk have legal protection under the federal Species at Risk Act (SARA 2002). Wind turbine monitoring can serve as a regulatory tool to support compliance in reducing impacts to species at risk (Dorey and Walker 2018). Further research is required to determine which monitoring protocols effectively reduce bird mortality associated with wind energy developments (Beston et al.2015; May et al.2015; Parisé and Walker 2017). The goal of this pilot study was to test the efficacy of sensory deterrents, including a predator owl model (visual) and bioacoustics calls (audio), for reducing bird mortalities at wind energy facilities.

Predator models have been widely studied for a variety of other uses (e.g. DeHaven 1971; Howard et al. 1985; Conover 1985; Knittle and Porter 1988; Rensel and Wilder 2012), but have not been studied at wind turbines. Target species, food types, location, time of day, season, and model used can all influence predator model effectiveness (Marsh et al. 1992). Deterrent effects demonstrated were often short-term, because birds habituate to the models due to lack of reinforcement from painful or lethal experiences (Marsh et al. 1992). However, introducing deterrents under different circumstances may 
be effective. Furthermore, if models are effective at deterring bird species even for a short time, they could be useful in reducing collisions when used selectively during periods of high avian activity. Use of predator models at wind turbines requires a different line of inquiry compared to previous studies, reflecting different target species, habitat, and models used. Predator owl deterrents could be more effective at wind turbines than in other situations, because turbine structures do not attract birds with food, as do crops or feeders.

Bioacoustic techniques have been implemented to deter birds in other instances, including landfills (Baxter 2000), airports (Blokpoel 1976), fish-rearing ponds (Andelt et al. 1997) and along highways (Conklin et al. 2009). Bioacoustic calls are thought to be the most effective audio deterrent for birds, because they invoke a natural fear response (Marsh et al. 1992). Sound is socially important to birds, as they can discern details in each sound and differentiate among conspecifics, harmless species, and potential predators (Congdon, 2015). Audio deterrents in the form of predator and alarm calls have been found effective for small areas over short periods of time, and could be used in similar situations to deter birds from wind turbines (May et al.2015). Past research suggests that many species recognize alarm calls of other species, allowing a playback of both predator calls and alarm calls to be more effective by invoking fear from multiple species (Magrath et al. 2009), causing the birds to leave the area.

The objective of this study was to test the effectiveness of visual and audio deterrents in deterring birds from areas near wind turbines, by deploying a predator owl model deterrent paired with an audio recording of predator and alarm calls. These bioacoustic calls were intended to draw attention of post-breeding and migrating songbirds to the owl model, helping to identify an immediate threat which could deter these birds from open areas near turbines, where they may be at risk of collision with turbine structures.

\section{METHODS}

\section{Study Location and Timing}

This study was conducted at a wind farm site located in Halifax Regional Municipality approximately $20 \mathrm{~km}$ northwest of Halifax, Nova Scotia, Canada (Fig 1). This wind farm includes 5 turbines with an installed capacity of $10 \mathrm{MW}$. The turbines are situated linearly, 


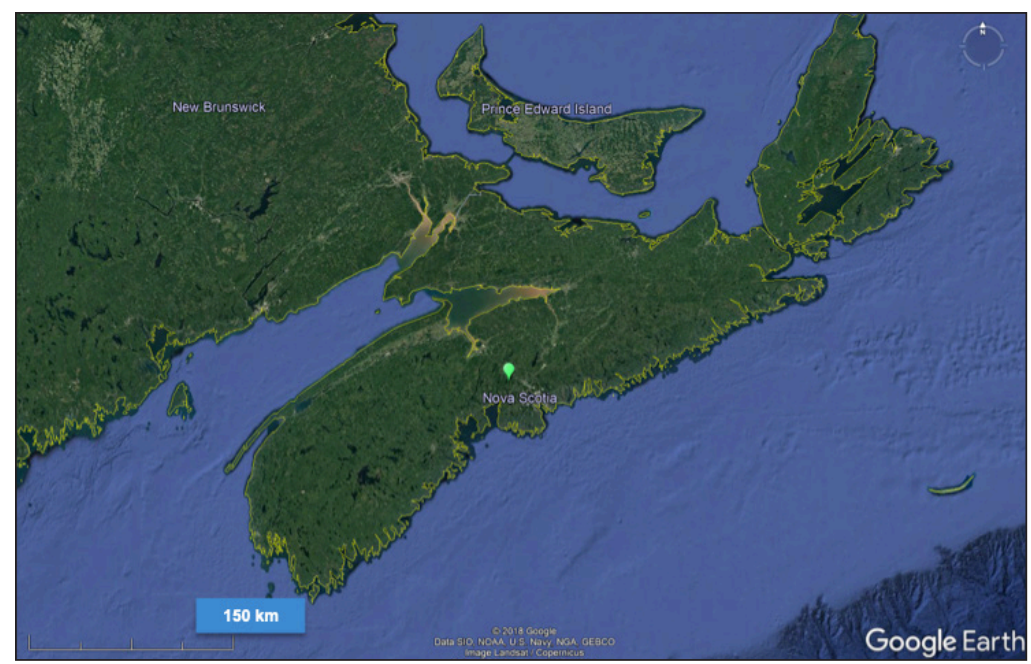

Fig 1 Study location, showing relative position of the wind farm $20 \mathrm{~km}$ northwest of Halifax, Nova Scotia, Canada.

approximately 400-700 m apart. The site encompasses 282 ha of diverse landscape, including softwood, hardwood and mixed wood forests, a power line corridor, urban areas, clear cuts, roads, dead stands, wetlands, and marshes. The site is located approximately $20 \mathrm{~km}$ from the Atlantic coast. The elevation of the site is approximately $150 \mathrm{~m}$, similar to the surrounding land.

The study was conducted from 22 August to 16 September 2016, during the early fall bird migration period. This period was selected to capture peak bird movements across the site, allowing observation of both migrating and resident birds engaged in a range of behaviours including foraging, high and low flight patterns, and migratory stopover.

\section{Data Collection}

Efficacy of model owls and predator calls in deterring birds from the area near wind turbines was assessed by monitoring bird flight paths and the number of bird passes and bird calls, using human observers during four trials. Deterrents and controls were implemented and monitored simultaneously 12 times for each of four turbines. Turbines were monitored three times per week on Monday, Wednesday and Friday. Each turbine was continuously monitored using an observer for 20 min., starting at sunrise. The total survey time was four hours for each deterrent and 16 hours for the entire study. 
Date, time, weather, turbine number, and trial type for each trial and turbine were recorded on a field sheet. A table with different bird flight behaviors on the field sheet was used to record whether the bird flew directly over the turbine, stayed within the tree-line, or flew over the turbine pad but changed its flight path. The observer recorded the number of bird passes and flight paths, and whether the bird was flying or calling. The observation area included a 50 $m$ radius from the turbine, with bird movements observed from the entrance to the turbine base.

The four trials used in this study were: Trial \#1: Visual deterrent; Trial \#2: Visual and audio deterrents; Trail \#3: Rotating Control turbine with no deterrent; and Trail \#4: Stationary Control turbine with no deterrent. The first trial used a Bird-X Prowler Owl with moving wings, perched on a $2.5 \mathrm{~m}$ section of polyvinyl chloride (PVC) pipe within $50 \mathrm{~m}$ of the turbine. The second trial included the Prowler Owl paired with predator calls and alarm calls. The predator call was of a Red-tailed Hawk (Buteo jamaicensis). Alarm calls were played from Ovenbirds (Seiurus aurocappilla) and White-throated Sparrows (Zonotrichia albicollis), two of the most common species found during pre- and post-construction monitoring. A mixture of predator calls and alarm calls were used to provide variation and portray a realistic threat. Playback was set up to run $24 \mathrm{~h} /$ day for the duration of the study.

The StorMP3 speaker was selected to play calls because it was water-resistant, had internal storage, and was powered by batteries lasting $>72 \mathrm{~h}$. This was essential because the speaker was required to operate for a minimum of $48 \mathrm{~h}$ between site visits and battery changes. The speaker was placed in a plastic casing with holes cut out so that its sound was not muffled. An audio file was created using version 2.1.2 of the Audacity ${ }^{\circledR}$ recording and editing software (Audacity Team 2016), using the Xeno-canto website to compile various Red-tailed Hawk, Ovenbird, and White-throated Sparrow calls (Cruikshank 2012; 2014; Price 2012; Davis 2014; Marvin 2015; 2014; Grosselet 2016; St. Michel 2016). Multiple calls for each species were used to simulate variety.

As bird numbers in the area of the turbines vary daily during the migration period, all trials occurred on the same dates. Trials rotated among turbines every second monitoring day, to control for different habitat and bird abundances at different turbines, except for the stationary control which remained at the same turbine throughout 
the study period. This control provided base-line bird counts without interference from bird deterrents, as the habitat at this location was similar to that found over the majority of the wind farm site. This was in contrast to the rotating control which was moved among turbines, to help indicate changes in base-line bird numbers resulting from the effect of deterrents at each turbine location during the previous monitoring day.

\section{Data Analysis}

Field sheets were transcribed into Microsoft Excel. Data were separated into total bird observations and calls heard versus birds flying. Data were also analyzed to detect differences in how birds responded to each of the deterrents at each turbine. Data were entered in VassarStats (Lowry 2016). A one-way analysis of variance followed by a Tukey's test was conducted to determine whether differences between trials were significant.

\section{RESULTS}

Table 1 describes the number of birds observed during each of the implemented trials. Each total is also separated into those birds that were observed flying and those that were only audible, and the abundance at each individual turbine are presented.

Table 1 Observed and audible bird occurrences and individual turbine bird abundances.

\begin{tabular}{lccrccc}
\hline & Observed & Audible & Total & T1 Totals & T2 Totals & T4 Totals \\
\hline Owl Model Alone & 58 & 43 & 101 & 13 & 62 & 25 \\
With Bioacoustic Calls & 60 & 23 & 83 & 18 & 34 & 31 \\
Rotating Control & 60 & 52 & 112 & 37 & 57 & 18 \\
Stationary Control & 47 & 41 & 88 & NA & NA & NA \\
\hline
\end{tabular}

No significant difference was found in the number of birds observed during each trial ( $\mathrm{F}=0.43, \mathrm{P}=0.73$; Fig 2$)$, nor was there a significant difference between the number of birds observed flying and the number heard $(\mathrm{F}=0.11, \mathrm{P}=0.95 ; \mathrm{F}=1.87, \mathrm{p}=0.15)$. However, slightly fewer audible calls were noted when bioacoustic calls were played, compared to the owl deterrent by itself or to the control (Fig 3). This suggests that birds tended to fly, rather than call, when the bioacoustic calls were played with the owl deterrent, although differences 


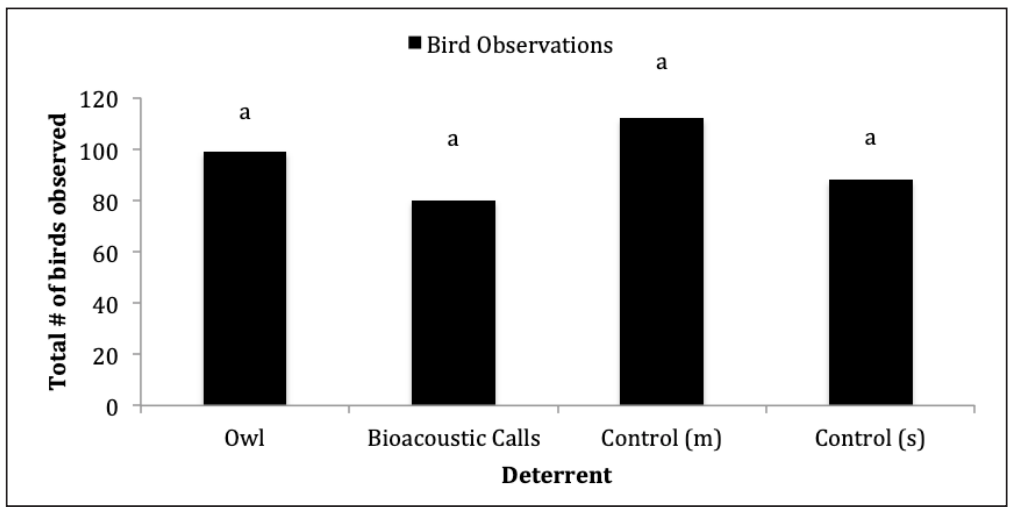

Fig 2 Effect of deterrent type on the total number of birds observed over 12 sampling events. Differences were tested for significance using a one-way ANOVA, followed by a Tukey's test. Bars with same letters represent data that were not significantly different at the $\mathbf{P}<0.05$ level. Values represent total bird abundance so error bars not included.

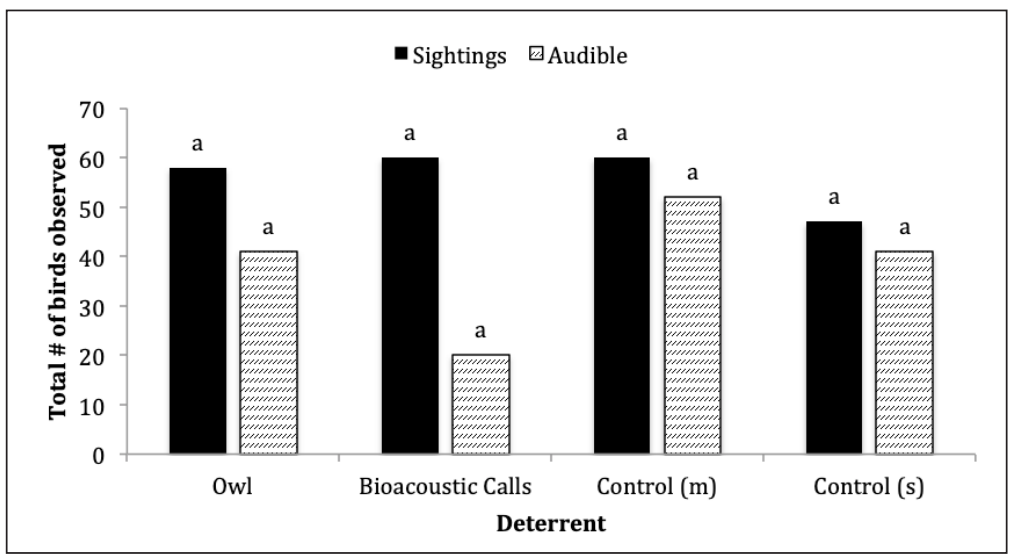

Fig 3 Effect of deterrent type on the total number of birds observed flying (black bars) and the number only heard calling (horizontally-stippled bars) over 12 sampling events. Differences were tested for significance using a one-way ANOVA, followed by a Tukey's test. Bars with same letters represent data that were not significantly different at the $\mathbf{P}<0.05$ level. Values represent total bird abundance, so error bars not included.

were not statistically significant $(\mathrm{F}=2.37, \mathrm{P}=0.12$, Fig 3). Abundance of birds observed at each turbine were significantly different, with turbine two showing the highest abundance $(\mathrm{F}=5.13, \mathrm{p}=0.01$, Fig 4).

Although this effect was controlled for, low bird abundance was noted on most monitoring days and, with only 12 monitoring days in 


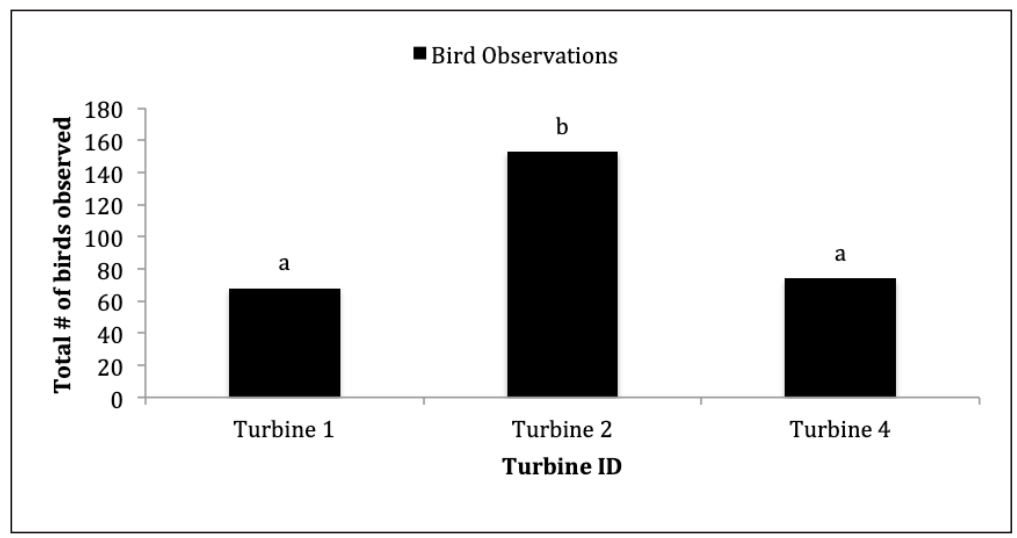

Fig 4 Effect of turbine location on the total number of birds observed over 12 sampling events. Differences were tested for significance using a one-way ANOVA, followed by a Tukey's test. Bars of the same letter represent data that are not significantly different, and bars with different letters represent data that differ significantly at the $\mathrm{P}<0.05$ level.

Table 2 Total bird observations for each deterrent on each day for the study period.

\begin{tabular}{lccccc}
\hline & \multicolumn{5}{c}{ Total Bird Counts for Each Deterrent } \\
Date & Owl & Predator Call & Control (m) & Control (s) & Total Daily \\
\hline Aug-22 & 18 & 3 & 3 & 1 & 25 \\
Aug-24 & 8 & 4 & 7 & 6 & 25 \\
Aug-26 & 2 & 0 & 2 & 3 & 7 \\
Aug-29 & 1 & 4 & 4 & 5 & 14 \\
Aug-31 & 4 & 8 & 14 & 5 & 31 \\
Sep-02 & 9 & 5 & 23 & 8 & 45 \\
Sep-05 & 19 & 6 & 14 & 9 & 48 \\
Sep-07 & 17 & 15 & 13 & 13 & 58 \\
Sep-09 & 4 & 4 & 4 & 6 & 18 \\
12-Sep & 6 & 26 & 8 & 16 & 56 \\
14-Sep & 3 & 0 & 9 & 11 & 23 \\
16-Sep & 8 & 5 & 11 & 5 & 29 \\
Total & 99 & 80 & 112 & 88 & 379 \\
Average & 8.25 & 6.67 & 9.33 & 7.33 & 31.58 \\
Standard Error & 1.84 & 2.09 & 1.75 & 1.24 & 4.77 \\
\hline
\end{tabular}

the study, even one day with high abundance at a deterrent had the potential to skew the data. Total daily observations for each trial are presented in Table 2.

However, though abundance at turbine two was observed to be higher, when bioacoustics calls were played, the abundance of birds 


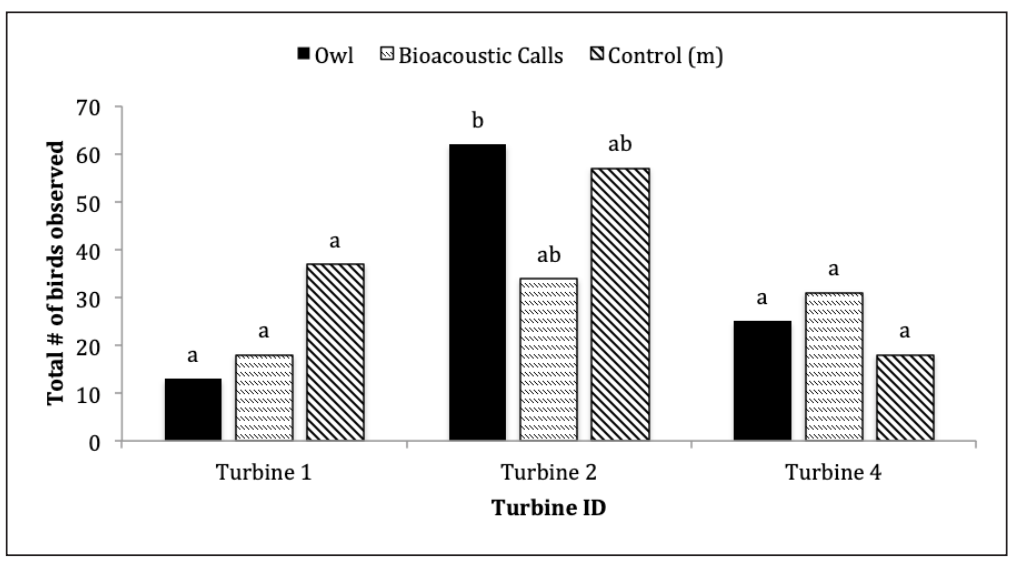

Fig 5 Effects of each deterrent type at each of three turbine locations over 12 sampling events. Black columns represent the total number of birds observed with the owl deterrent, horizontally-stippled columns represent total birds observed with the predator call deterrent, and diagonally-stippled columns represent total birds observed with no deterrent (control). Differences were tested for significance using a one-way ANOVA, followed by a Tukey's test. Bars of the same letter represent data that are not significantly different, and bars with different letters represent data that differ significantly at the $\mathbf{P}<0.05$ level.

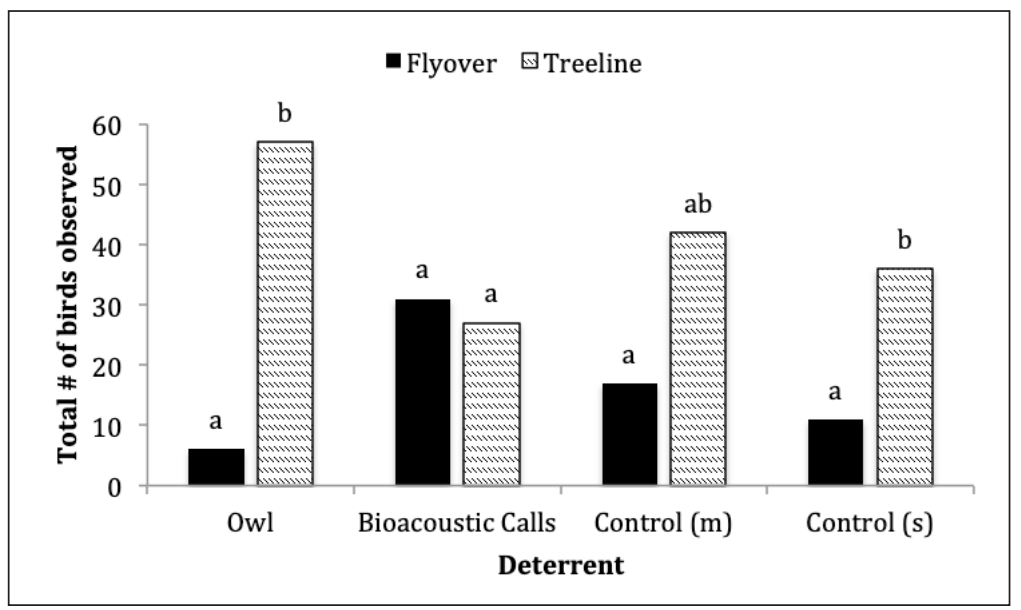

Fig 6 Effect of deterrent type on flight paths taken by birds, over 12 sampling events. Filled columns represent the total number of birds that flew directly over the turbine base, and hatched columns represent total number of birds that stayed among the tree-line. Differences were tested for significance using a one-way ANOVA, followed by a Tukey's test. Bars of the same letter represent data that are not significantly different, and bars with different letters represent data that differ significantly at the $\mathrm{P}<0.05$ level. 
at turbine two was lower than other trials at this turbine (Fig 5). Significantly more birds stayed among the tree-line than flew over the turbine pad when only the owl was present $(\mathrm{F}=9.57, \mathrm{P}=0.005$, Fig 6). The rotating control also had a similar effect of reduced numbers, but the difference was not significant $(\mathrm{F}=1.9, \mathrm{P}=0.18)$. The numbers of birds observed in the tree-line and over the open turbine pad were not significantly different, nor was an effect observed for bioacoustic calls $(\mathrm{F}=0.05, \mathrm{P}=0.83$, Fig 6$)$.

\section{DISCUSSION}

\section{Efficacy of Deterrents}

The owl deterrent did not significantly deter birds from approaching the wind turbines, when present either on its own or with bioacoustic calls. However, some effects identified suggest that bioacoustic calls may have had some effect. More birds were observed flying compared to calling when bioacoustic calls were paired with an owl deterrent, contradicting other studies which found that passerine birds often gave alarm calls when hawks were present, at frequencies that made it difficult for hawks to locate the calling bird (Marler 1955; Klump 2000). However, alarm calls that were played in the background of the bioacoustic recording could have caused the fleeing effect. Fallow et al. (2013) found that all birds fled when a natural or synthetic call of a different species was played. Aerial alarm calls usually represent a flee call identifying a fast-moving threat that requires a prompt response (Bradbury and Vehrencamp 1998). It is possible that alarm calls in the bioacoustic playback caused nearby bird populations to flee or avoid the turbine area, rather than join in alarm-calling, as lower call rates and lower abundance with bioacoustic calls were observed at turbine two. Fallow et al. (2013) found a higher probability of birds fleeing when alarm calls were played at a frequency of $9 \mathrm{kHz}$, which is similar to the frequency of the alarm calls played in the background of predator calls on an audio track. As effects observed in this pilot study were inconclusive, further studies are required to determine whether model owls in combination with bioacoustic calls would be effective at deterring birds from flying over the wind turbine pad.

There was a significant difference in the abundance of birds observed at each turbine, with higher numbers recorded at turbine two. This could be a result of turbine two having the most diverse 
landscape, including a swamp, a managed reservoir and roadway, and was across from a water treatment facility.

\section{Study Limitations and Future Research Directions}

Statistical power was a limitation of this pilot study, but future deterrent monitoring should incorporate more replicates distributed across more turbine sites to allow for improved statistical comparison to determine the effectiveness of these mitigative measures.

Bird species targeted in this study differ from those in studies attempting to deter pest species (e.g. crows, starlings, grackles, gulls) (Conover and Perito 1981; Conover 1979; 1985). Most turbine mortality events impact nocturnally migrating songbirds (WEBBMD 2016), which may react differently than pest species. Therefore, future studies should also be designed to assess impacts on these species.

Implementing the visual and bioacoustic deterrents at several wind energy sites and over entire spring and fall post-construction monitoring periods would provide more data, with the potential to show some of the identified effects as significant. Future studies could also benefit from more effective technology. Although the StorMP3 speaker was easily heard at the level of the turbine pad, it is unknown whether it was always audible at the height of the turbine blades. Birds may be unable to hear playback calls at turbine height when combined with wind and turbine noise. Furthermore, testing different owl perching positions could offer insight into the effects of predator visibility on deterrent effectiveness. Placing the perched owl higher could increase the visibility of the predator to incoming birds as they approach the turbine pad.

During each trial, acoustic monitors also recorded night flight calls to determine differences in bird abundance through the night. However, the SongMeter3 acoustic monitors used could not clearly capture flight calls and could therefore, not be used for the remainder of the study. Even when calls may have been identified on the spectrogram, differentiating it from whistles from the wind or blade was not possible.

Wind developers face similar and larger-scale challenges when implementing mitigation measures and consistently-effective mitigation measures are still to be identified. Many studies found conflicting results, mainly because the effectiveness of mitigation measures is usually species-specific (Conover 1985; Boag and Lewin 1980; Rensel and Wilder 2012). 
May et al. (2015) suggest implementing measures that are specific to each site and to the bird species present, as different species often react differently near turbines. Relevant data could be gathered during baseline pre-construction data surveys. Although baseline studies must be conducted, further monitoring is needed once mitigation measures are implemented to determine their effectiveness, requiring additional resources. Due to the large investment of resources required to monitor site and species factors, as well as post-implementation monitoring, wind developers would likely prefer to implement measures that are known to be effective. However, effective measures at wind turbine sites are not certain and few studies have conducted research at wind turbines (e.g. Haugan 2014; Laufer Wind Group 2016; Young et al. 2003), while many measures are reliant on labratory testing (e.g. Avery et al. 1996; Hodos 2003; Poot et al. 2008; Long et al. 2011).

It is difficult to determine whether measures are effective if actual mortality rates are unknown, due to insufficient data available in the WEBBMD, particularly from the Atlantic region (Parisé and Walker 2017). It is widely reported that mortality rates at wind turbines are underestimated, contributing to a lack of complete understanding of interactions between birds and wind turbines (e.g. Erickson et al. 2005; Bernardino et al. 2013; Marques et al.2014; Huso and Dalthorp 2014). Parisé and Walker (2017) suggested recently that developers should submit mortality data to WEBBMD for a better understanding of bird mortality rates in Nova Scotia. This could be a regulatory requirement, as these data would help developers make more-informed decisions, by understanding the mortality rates in relation to species, location, geography, number of turbines, and layout of farms.

Further challenges in determining effective measures relate to public acceptance. Communities often have concerns related to sight and sound of turbines and may perceive changing turbine structures negatively. Additionally, noise from operating turbines is often controversial, and implementing audio deterrents may pose additional challenges to turbine acceptance. The bioacoustics approach considered here may blend with natural background sounds. However, other audible avian harassment sources, such as the use of air cannon techniques, may not be well-reviewed by the public. 


\section{CONCLUSION}

Wind energy is one of the fastest-growing renewable sources of electricity globally, as a clean alternative to fossil fuels. Though beneficial at reducing greenhouse gas emissions, wind turbines are known to cause avian and bat mortality through collisions. Current practice uses strategic planning, such as effective siting and lighting, and an understanding of bird behavior to reduce bird collision rates. However, there is a lack of confidence in the effectiveness of active mitigation measures, such as bird scaring, due to inconsistent monitoring protocols and reporting. With additional research and testing of deterrents and mitigation measures, effective measures may be identified to help reduce environmental harm from the growing wind industry.

Acknowledgements We thank Strum Consulting and Mitacs Accelerate (IT07560) for funding this research, two anonymous reviewers who provided valuable comments that enhanced the quality of this paper, and Liam Goulding, a summer student at Strum Consulting from Saint Mary's University for assisting with data collection. There are no conflicts of interest identified in relation to this study.

\section{REFERENCES}

Andelt, W.F., Woolley, T.P., \& Hopper, S.N. (1997). Effectiveness of barriers, pyrotechnics. Wildlife Society Bulletin 25(3): 686-694.

Audacity Team. (2016). Audacity(R): Free audio editor and recorder. Version 2.1.2.

Avery, M.L., Decker, D.G., Humphrey, J.S. et al. (1996). Mint plant derivatives as blackbird feeding deterrent. Crop Protection 15(5): 461-463.

Baisner, A.J., Andersen, J.L.,Findsen, A. et al. (2010). Minimizing collision risk between migrating raptors and marine wind farms: development of a spatial planning tool. Environmental Management 46(5): 801-808.

Bird Studies Canada. (2018). Wind Energy Bird and Bat Monitoring Database. Available via www.bsc-eoc.org/birdmon/wind/main.jsp. Accessed February 22, 2018.

Baxter, A. (2000). Use of distress calls to deter birds from landfill sites near airports. In: Bird Strike Committee Proceedings, Calgary, Alberta, August 2001.

Bernardino, J., Bispo, R., Costa, H. et al. (2013). Estimating bird and bat fatality at wind farms: a practical overview of estimators, their assumptions and limitations. New Zealand Journal of Zoology 40: 63-74. 
Beston, J.A., Diffendorfer, J.E., \& Loss, S. (2015). Insufficient sampling to identify species affected by turbine collisions. The Journal of Wildlife Management 79(3): 513-517.

Blokpoel, H. (1976). Bird hazards to aircraft. Toronto, Canada.

Boag, D.A., \& Lewin, V. (1980). Effectiveness of three waterfowl deterrents on natural and polluted ponds. Journal of Wildlife Management, 44, 145-154.

Bradbury, J.W., \& Vehrencamp,S.L. (1998). Web Topic 2.3: Quantifying and Comparing Sound Amplitudes. Principles of animal communication. 2nd edition. Available via sites.sinauer.com/animalcommunication2e/ about.html. Accessed 18 Aug 2017.

Calvert, A. M., Bishop, C.A., Elliot, R.D., Krebs, E.A. Kydd, T.M., Machtans, C.S., \& Robertson, G.J.2013. A synthesis of human-related avian mortality in Canada. Avian Conservation and Ecology 8(2): 11.

Canadian Wind Energy Association (CanWEA). (2017). Canada's current installed capacity. Available via canwea.ca/wind-energy/installedcapacity/. Accessed 2 April 2018.

Congdon,J.V. (2015) Chickadee behavior response to varying threat levels of predator and conspecific calls. International Journal of Comparative Psychology, 29, 1-21.

Conklin, J.S., Delwiche, M.J., Gorenzel, W.P. et al. (2009). Deterring cliff-swallow nesting on highway structures using bioacoustics and surface modification. Human-Wildlife Interactions. Available via digitalcommons.unl.edu/cgi/viewcontent.cgi?article=1024\&context $=$ hwi. Accessed 18 Aug 2017.

Conover, M.R. (1979). Response of birds to raptor models. Bird Control Seminar Proceedings. Nebraska USA.

Conover,M.R.(1985). Protecting vegetables from crows using an animated crow-killing owl model. Journal of Wildllife Management 49: 643-645.

Conover,M.R., \& Perito, J.J.(1981). Response of starlings to distress calls and predator models holding conspecific prey.Z. Tierpsychol.57, 163-172.

Cruikshank, I. (2012). Red-tailed Hawk (Buteo jamaicensis) call. Available via www.xeno-canto.org/159472]. Accessed 15 Aug 2016.

Cruikshank, I. (2014). Red-tailed Hawk (Buteo jamaicensis) call. Available via www.xeno-canto.org/183586. Accessed 15 May 2016.

Davis, T. (2014). White-throated Sparrow (Zonotrichia albicollis) alarm call. Available via www.xeno-canto.org/217366]. Accessed 15 Aug 2016

DeHaven, R.W. (1971). Blackbirds and the California rice crop. Rice Journal 74: 11-12.

Dorey,K.,\& Walker, T.R.(2018). Limitations of Threatened Species Lists in Canada: A Federal and Provincial Perspective. Biological Conservation 217: 259-268.

EGSPA (Environmental Goals and Sustainable Prosperity Act). (2007), s. 4. 
Erickson, W.P., Johnson, G.D., \& Young, D.P. (2005). A Summary and Comparison of Bird Mortality from Anthropogenic Causes with an Emphasis on Collisions. In: Ralph, C. John; Rich Terrell D., editors 2005. Bird conservation implementation and integration in the Americas: Proceedings of the third international partners in flight conference. California, U.S.A. 2002.

Fallow, P.M., Pitcher, B.J., \& Magrath, R.D. (2013). Alarming features: birds use specific acoustic properties to identify heterospecific alarm calls. Proceedings of the Royal Society B 280(174). doi: 10.1098/rspb.2012.2539.

Government of Canada. (1994). Migratory Bird Convention Act S.C. 1994. cc. 22.

Government of Canada. (2002). SARA (Species at Risk Act) S.C., 2002, c. 29.

Grosselet, M. (2016). Red-tailed Hawk (Buteo jamaicensis) flight call. Available via www.xeno-canto.org/327633. Accessed 15 Aug 2016.

Haugan, I. (2014). Five kilometers between life and death for the sea eagle. Science Nordic. Available via sciencenordic.com/five-kilometresbetween-life-and-death-sea-eagle. Accessed 28 Nov 2016.

Hodos, W. (2003). Minimization of Motion Smear: Reducing Avian Collisions with Wind Turbines. Available via citeseerx.ist.psu.edu/viewdoc/ download?doi=10.1.1.487.6608\&rep=rep1\&type=pdf. Accessed 18 Aug 2017.

Howard, W.E., Marsh, R.E., \& Corbett, C.W. (1985). Raptor perches: their influence on crop protection. Acta Zoological Fennica 173: 191-192.

Hull, C.L., Stark, E.M., Peruzzo, S. et al. (2013). Avian collisions at two wind farms in Tasmania, Australia: taxonomic and ecological characteristics of colliders versus non-colliders. New Zealand Journal of Zoology 40: 47-62.

Huso, M.M.P., \& Dalthorp, D. (2014). Accounting for unsearched areas in estimating wind turbine-caused fatality. Journal of Wildlife Management 78: 347-358.

Klump, G.M. (2000). Sound localization in birds. In: Dooling RJ, Fay RR, Popper AN (eds.) Competitive Hearing: Birds and Reptiles Spring, New York, p. 249-307.

Knittle, C.E., \& Porter, R.D. (1988). Waterfowl damage and control methods in ripening grain: an overview. Washington DC, U.S.A.

Laufer Wind. (2016). Laufer Wind's radar-activated obstruction lighting system meets FAA performance. Available via www.windsystemsmag. com/article/detail/1124/laufer-winds-radar-activated-obstruction-lighting-system-meets-faa-performance. Accessed 28 Nov 2016.

Long, C.V., Flint, J.A., \& Lepper, P.A. (2011). Insect attraction to wind turbines:does colour play a role? European Journal of Wildlife Research 57(20): 323-331.

Lowry, R. (2016). One-Way Analysis of Variance for Independent or Correlated Samples Web Calculation. Available via vassarstats.net/ anovalu.html. Accessed 13 Dec 2016. 
Magrath, R.D., Pitcher, B.J., \& Gardner, J.J. (2009). Recognition of other species aerial alarm calls: same language or learning another? Proceedings of the Royal Society B 276: 769-774.

Marler, P. (1955). Characteristics of some animal calls. Nature 176: 6-8.

Marsh, R.E., Erickson, W.A., \& Salmon, T.P. (1992). Scarecrows and predator models for frightening birds from specific areas. In: Borrecco J.E., March R.E. (eds.) Proceedings of the 15th Vertebrate Pest Conference March 1992.

Marvin,P.(2014). White-throated Sparrow (Zonotrichia albicollis) "pink" alarm calls, some in flight. Available via www.xeno-canto.org/232941. Accessed 15 Aug. 2016

Marvin,P.(2015). Red-tailed Hawk (Buteojamaicensis) call. [Downloaded 15/08/16 from: www.xeno-canto.org/307480].

Marques, A.T., Batalha,H., Rodrigues,S.et al. (2014). Understanding bird collisions at wind farms: An updated review on the causes and possible mitigation strategies. Biological Conservation 179: 40-52.

May, R., Reitan, O., Bevanger, K. et al. (2015). Mitigating wind-turbine induced avian mortality: Sensory, aerodynamic and cognitive constraints and options. Renewable and Sustainable Energy Review 42: 170-181.

Nova Scotia Power. (2017). How we make electricity. Available via www. nspower.ca/en/home/about-us/how-we-make-electricity/default.aspx. Accessed 2 Apr 2018.

Parisé,J., \& Walker,T.R.(2017). Industrial wind turbine post-construction bird and bat monitoring: A policy framework for Canada. Journal of Environmental Management 201: 252-259.

Poot, H., Ens, B.J., de Vries, H. et al. (2008). Green light for nocturnally migrating birds. Ecology Society 13: 47.

Price, L.G. (2012). White-throated Sparrow (Zonotrichia albicollis) alarm call, call. Available via www.xeno-canto.org/113097. Accessed 15 Aug 2016.

Rensel, L.J., \& Wilder, J.D. (2012). The effects of owl decoys and nonthreatening objects on bird feeding behaviour. Quercus: Linfield Journal of Undergraduate Research 1(4): 1-12.

Reyes, G.A., Rodriguez, M.J., Lindke, K.T. et al. (2016). Searcher efficiency and survey coverage affect precision of fatality estimates. The Journal of Wildlife Management 1496-1488: (8)80.

Saidur, R., Rahim, N.A., Islam, M.R. et al. (2011). Environmental impact of wind energy. Renewable and Sustainable Energy Review 15(5): 2423-2430.

Schuster, E., Bulling, L., \& Köppel, J. (2015) Consolidating the state of knowledge: a synoptical review of wind energy's wildlife effects. Environmental Management 331-300: (2)56.

Smallwood, K.S., Bell, D.A., Snyder, S.A. et al. (2010). Novel scavenger removal trials increase wind turbine-caused avian fatality estimates. Journal of Wildlife Management 1097-1089: (5)74.

Sovacool, B.K. (2013). The avian benefits of wind energy: A 2009 update. Renewable Energy 49: 19-24. 
Stenglein, J.L., Van Deelen, T.R., Wydeven, A.P. et al. (2015). Mortality patterns and detection bias from carcass data: An example from wolf recovery in Wisconsin. The Journal of Wildlife Management 79(7): 1173-1184.

St.Michel, M.(2016). Ovenbird (Seiurus aurocapilla) alarm call. Available via www.xeno-canto.org/319177. Accessed 15 Aug 2016.

The World Bank Group. (2016). Electric power consumption (kWh per capita). Available via data.worldbank.org/indicator/EG.USE.ELEC. KH.PC. Accessed 28 Nov 2016.

Wang, S., Wang, S., \& Smith, P. (2015). Ecological impacts of wind farms on birds: Questions, hypotheses, and research needs. Renewable and Sustainable Energy Reviews 44: 599-607.

Wind Energy Bird and Bat Monitoring Database (WEBBMD). (2016). Summary of the findings from post-construction monitoring report. Available via www.bsc-eoc.org/birdmon/wind/resources.jsp?dir=reports. Accessed 13 Dec 2016.

Young, D.P.,Erickson, W.P.,Stricklan.d,M.D.et al.(2003).Comparison of Avian Responses to UV-Light-Reflective Paint on Wind Turbines. Availi able via www.west-inc.com/reports/fcr_nrel.pdf. Accessed 18 Aug 2017.

Zimmerling, J.R., Pomeroy, A.C., d'Entremont, M. et al. (2013). Canadian estimate of bird mortality due to collisions and direct habitat loss associated with wind turbine developments. Avian Conservation and Ecology 8(2): 10. 